نقش حساسيت به فرسايش سازندهاى زمينشناسى در فرسايش و توليد رسوب (مطالعه موردى: زيرحوزههاى رودخانه دويرج استان سينان ايلام)

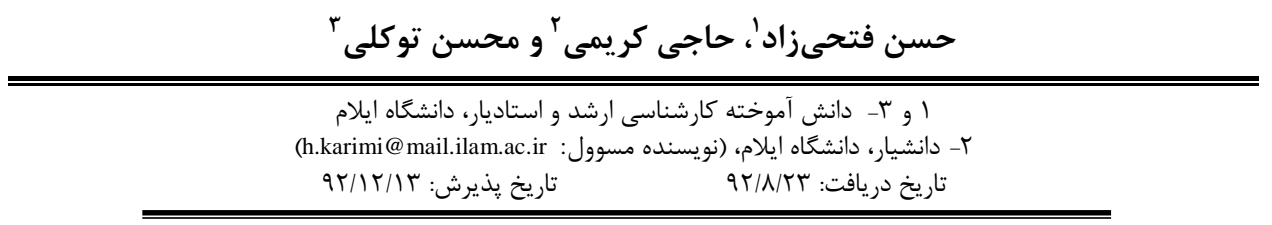

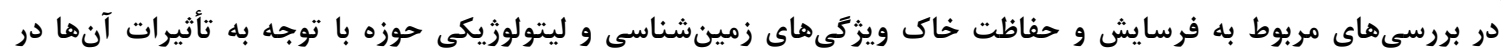

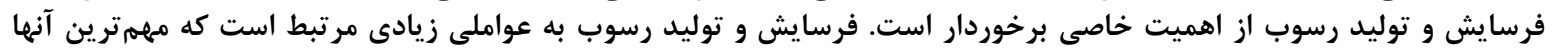

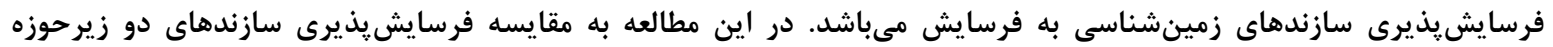

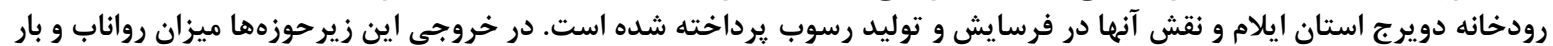

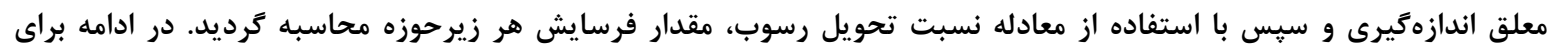

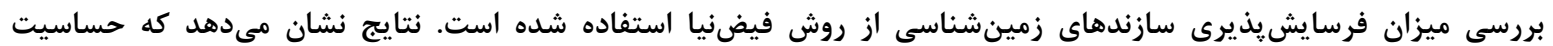

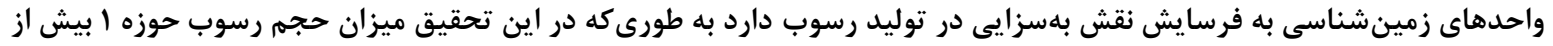

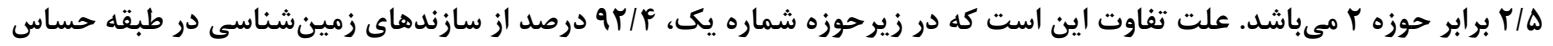

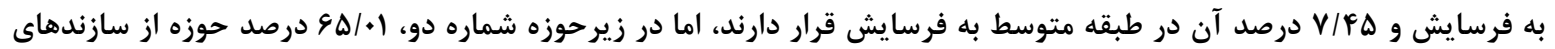

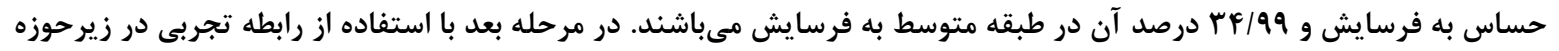

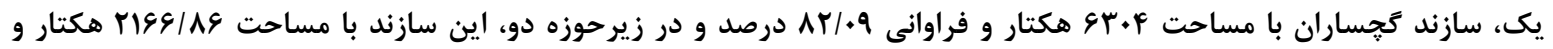

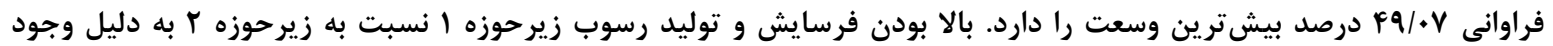

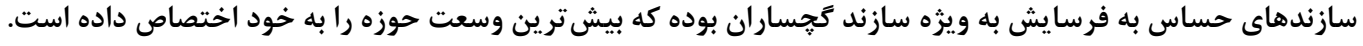

وازههاى كليدى: فرسايش، رسوب، سازندهاى زمينشناسى، روش فيضنيا، دويرج

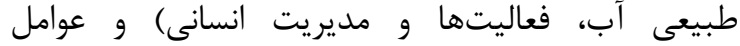

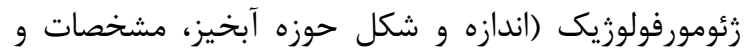

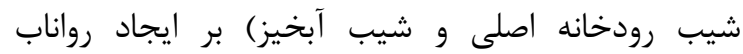

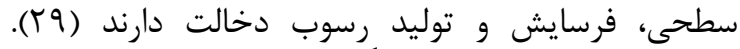

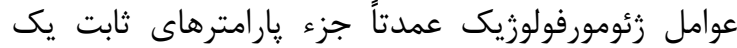

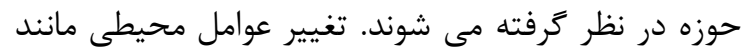

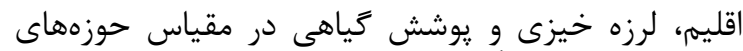

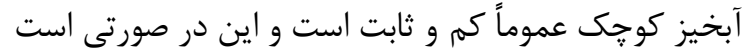

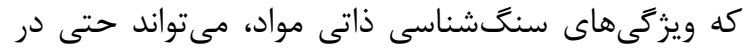

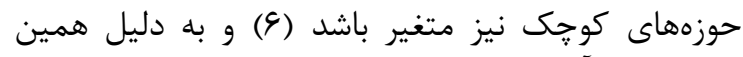

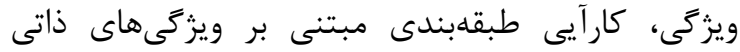

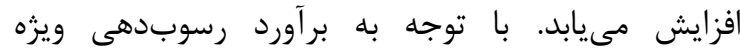

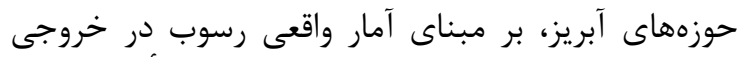

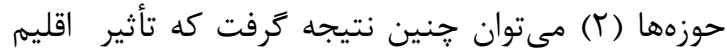

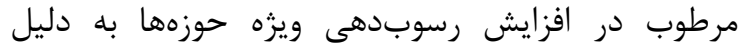

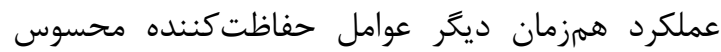

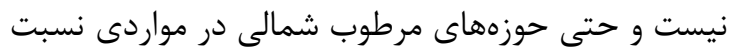

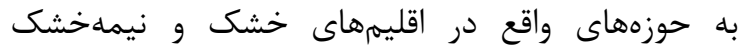

فرسايش خاك موجب كاهش عمق خاك، محتواى

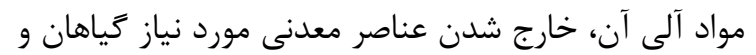

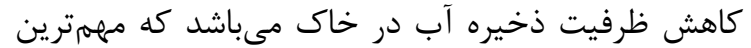

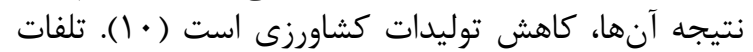

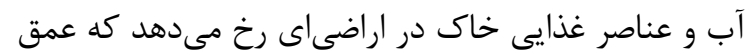

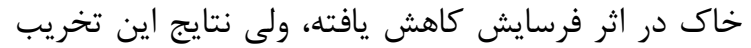

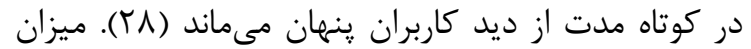

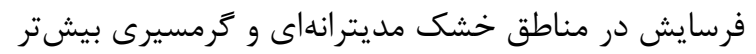

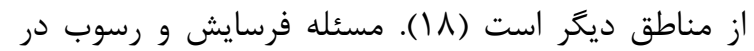

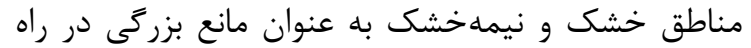

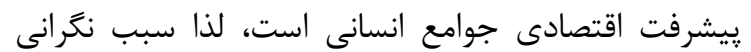

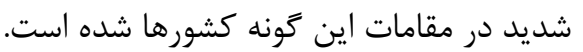

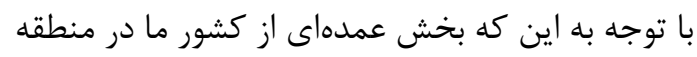

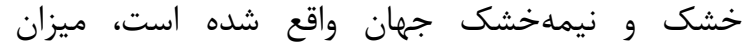

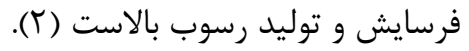

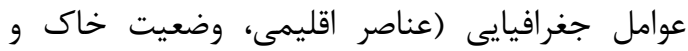
شرايط زمينشناسى، يوشش كَياهى، مخازن مصنوعى و و 


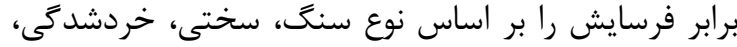

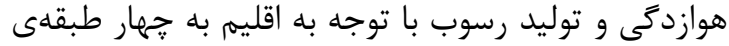

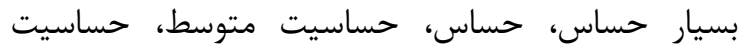

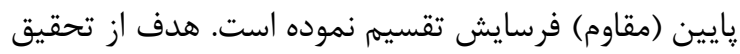

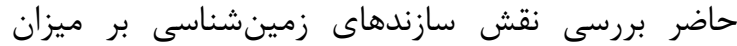

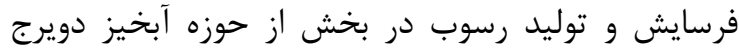
استان ايلام در طى يك ركَبار مى دباشد.

زيرحوزههاى مورد مطالعه در شمال حوزه آبخيز دويرج

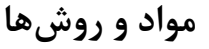 موقعيت منطقه}

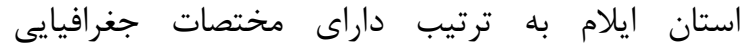
جغرافيايى "

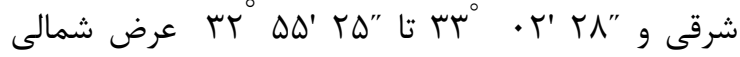

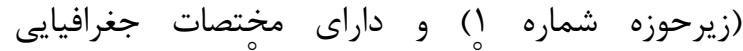
جغرافيايى "F شماره

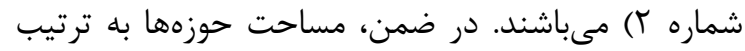
برابر با (

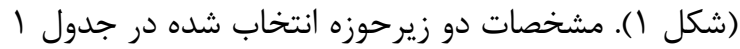

آمده است.
رسوبدهى ويزه كمترى دارند. بنابراين هر جند جند به طور

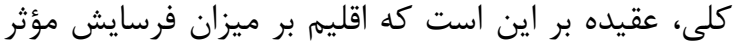

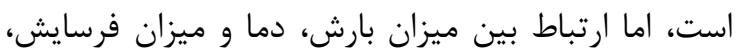

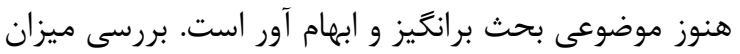

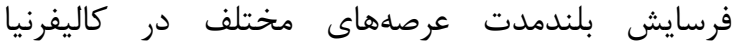
با استفاده از راديو نوكلوئيدها نشان (Sierra Nevada)

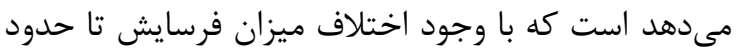

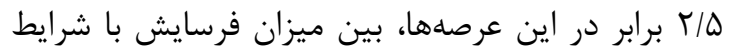

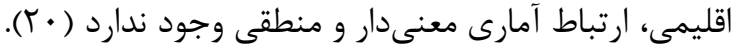

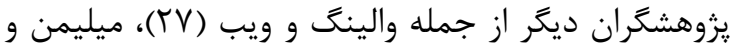

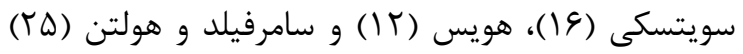

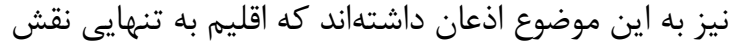

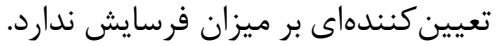

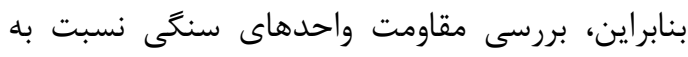

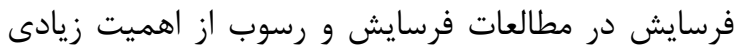

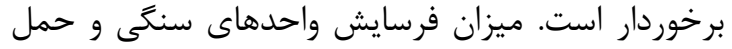

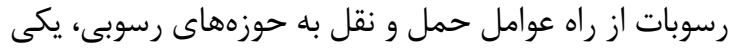

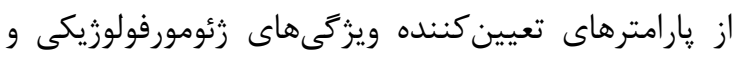

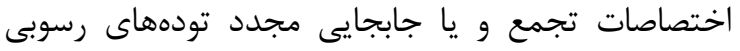

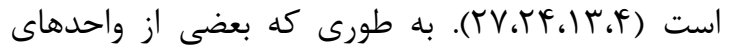

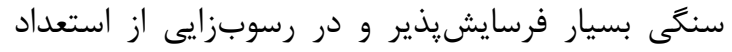

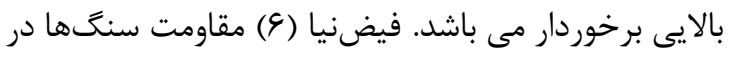

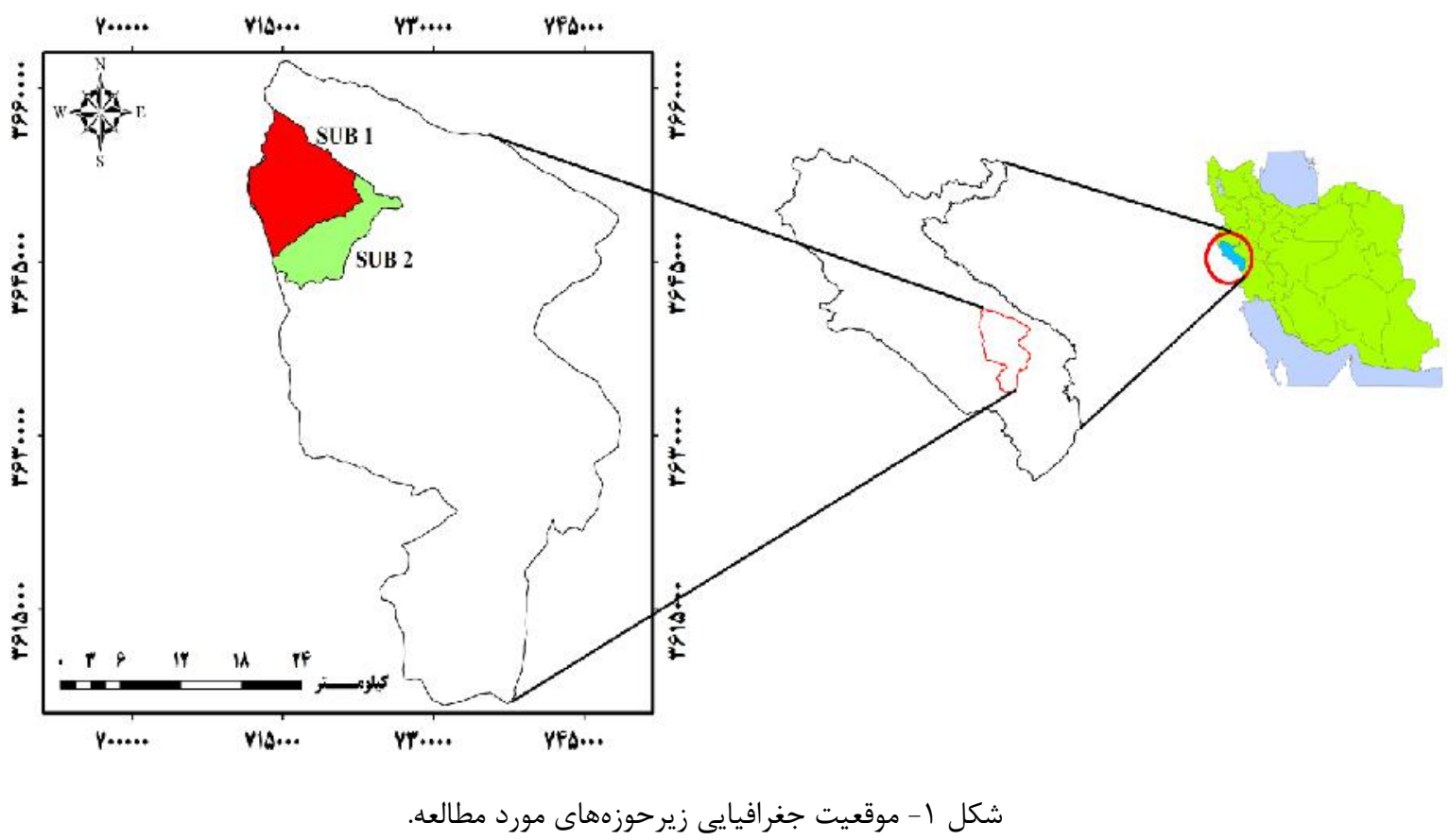




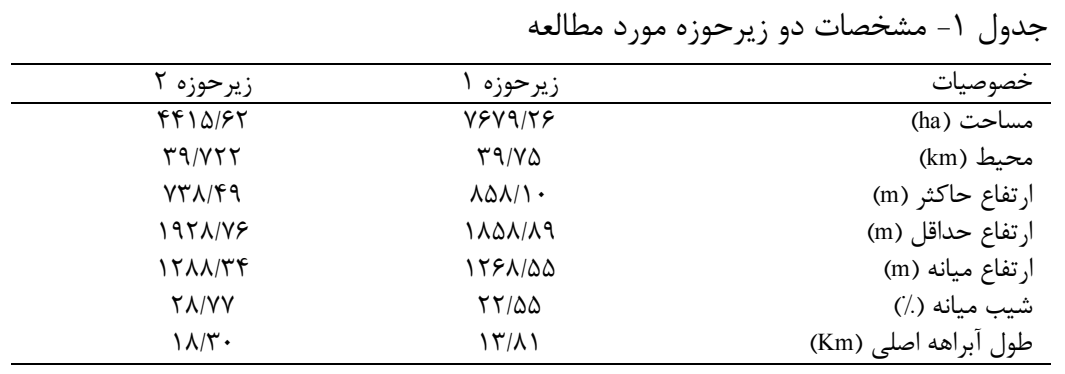

دورانهاى دوم، سوم و جهارم تا رسوبات جوان بستر در

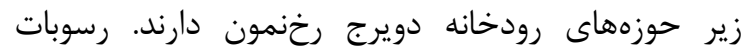

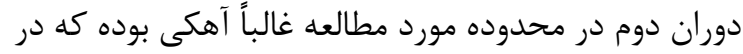

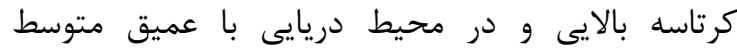

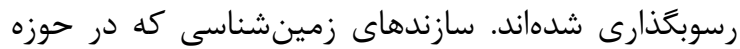

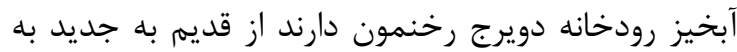

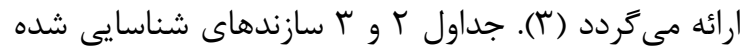

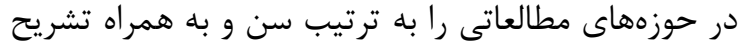

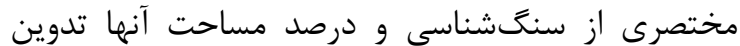

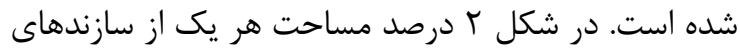

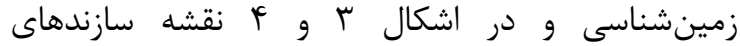

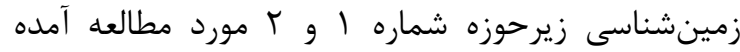

يزوهش حاضر دربارهى زمينشناسى و سازندها و ورئ زئن

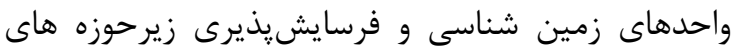

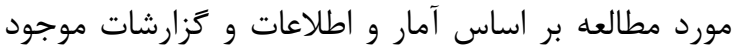

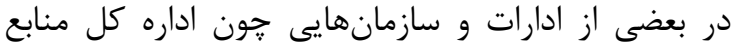

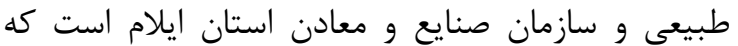

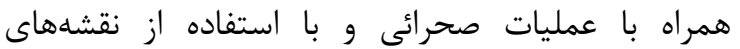

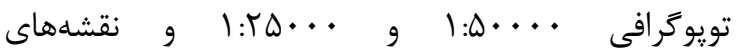

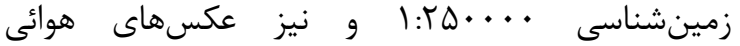

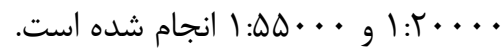

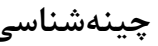
اطلاعات جينهشناسى منطقه مورد مطالعه از طريق

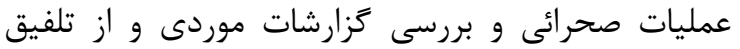

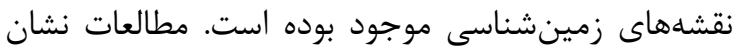

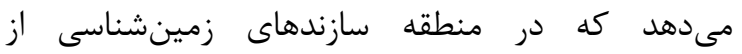

جدول r- سازندهاى سنَششناسى زيرحوزههاى مورد مطالعه

\begin{tabular}{|c|c|c|c|c|}
\hline فروانى (درصد) & مساحت زير حوزه Y (هكتار) & فروانى (درصد) & مساحت زيرحوزه ( (هكتار) & نام سازند \\
\hline $1 f / 94$ & $9 \Delta 9 / V 1$ & $9 / D 1$ & $V \pi \cdot \mid q 4$ & كواترنرى \\
\hline 1 & FF/TH & .194 & VT/MG & بختيارى \\
\hline $1 / 79$ & $\vee q / \cdot F$ & $1 / T \wedge$ & $q \Lambda / Q F$ & آغاجارى \\
\hline $\mathrm{Fq} / \cdot \mathrm{V}$ & TIS9/NG & $\Lambda r / \cdot 9$ & $q \pi \cdot r$ & كَّساران \\
\hline TT/VV & $1 \cdot \cdots \Delta / q \Gamma$ & 9/IV & EVT/VR & آسمارى \\
\hline $1 \cdot / 4 T$ & $49 \cdot / 1 V$ & - & - & يابده- كَر يَى \\
\hline $1 \cdots$ & FfiQ/GT & $1 \cdots$ & $V G \vee 9 / T V$ & مجموع \\
\hline
\end{tabular}

جدول r- گَترش سازندهاى زمينشناسى در زيرحوزههاى مورد مطالعه

\begin{tabular}{|c|c|c|c|c|}
\hline \multirow{2}{*}{ دوران } & دور سن & خصوصيات سنَ شناسى & علامت & 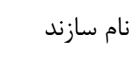 \\
\hline & هولوسن و يلئيستوسن & نهشتههاى رودخانه، آبرفت & Q & كواترنرى \\
\hline & يليوسن & كنعلومرا با دانههاى آهكى و جرتى & BK & بختيارى \\
\hline 祭 & ميوسن-يليوسن & ماسه سنَ و مارن قرمز & Aj & آغاجارى \\
\hline अ: & ميوسن & زييس، انيدريت مارن و آهك & GS & كَجساران \\
\hline & اوليخوسن- ميوسن & آهك فسيل دار و درز و شكاف دار & AS & آسمارى \\
\hline $\begin{array}{l}\text { 令 } \\
\text { ज़े: }\end{array}$ & ائوسن - هالئوسن & آهك مارنى نازك لايه و مارن & $\mathrm{Pd}-\mathrm{Gu}$ & يابده - "وريى \\
\hline
\end{tabular}



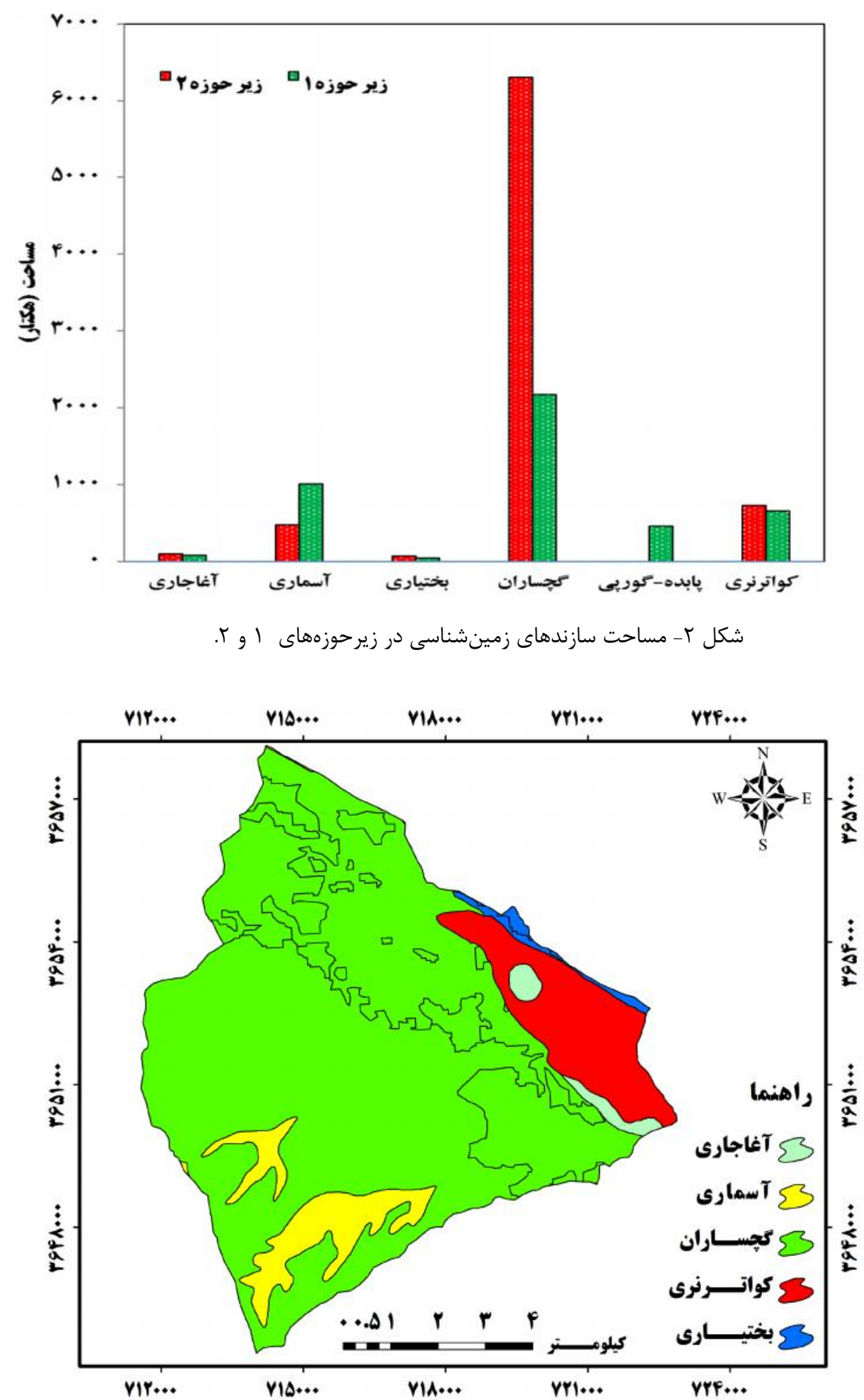

شكل r- نقشه سازندهاى زمينشناسى زير حوزه 1. 


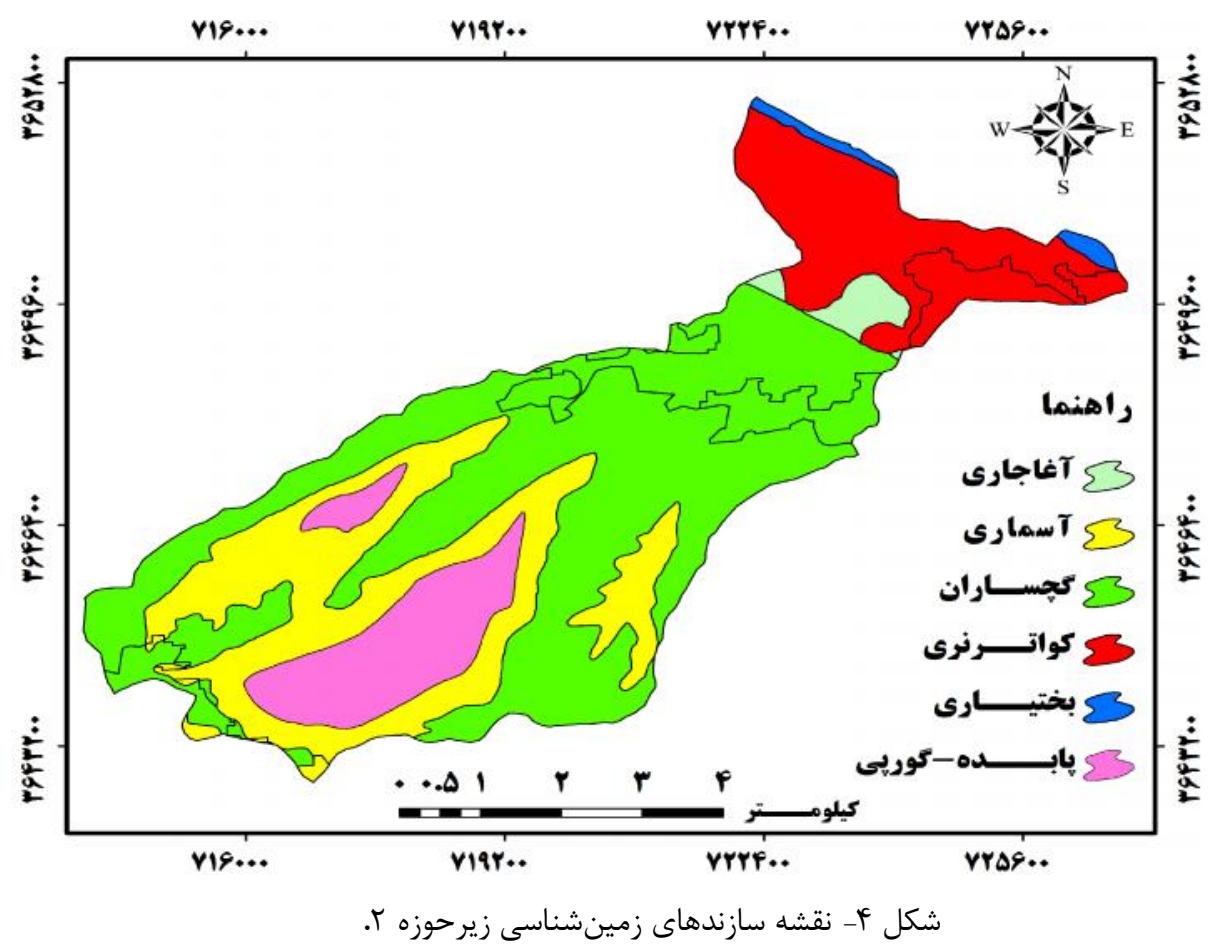

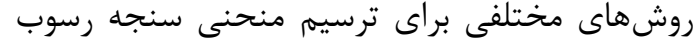

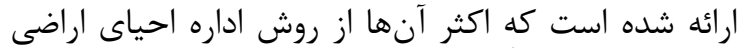

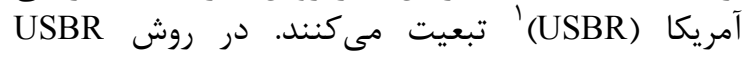
(19AV)

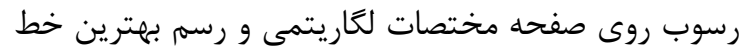

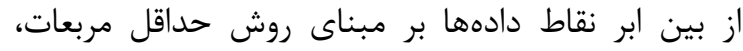

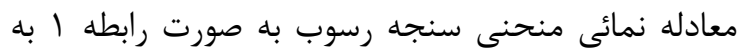
دست مى آيد. $Q_{S}=a Q_{w}^{b}$ رابطه (1)

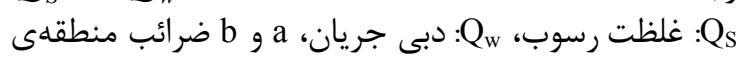
معادله.

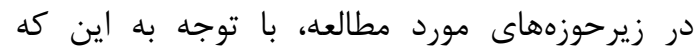

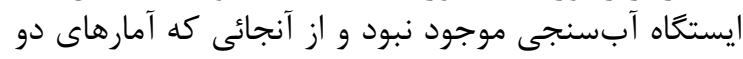

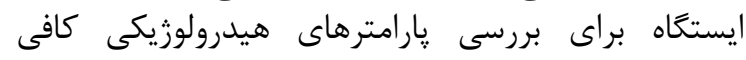

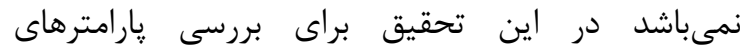

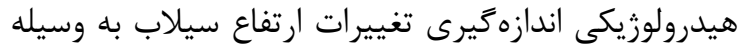

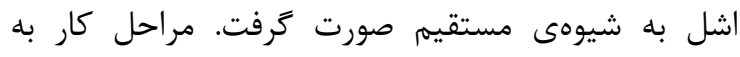
صورت زير مىباشد: - مئد

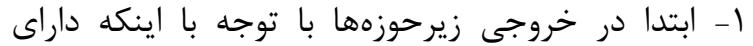

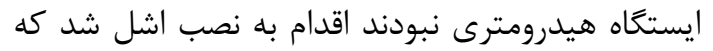

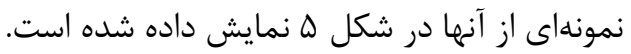

اندازهيرى دبى و نمونهبردارى رسوب

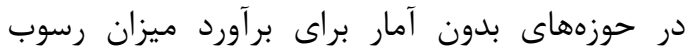

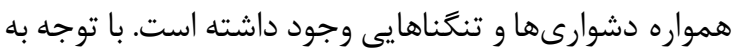

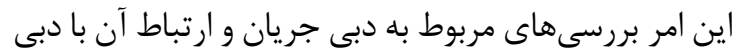

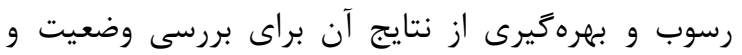

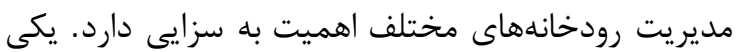

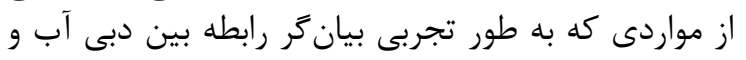

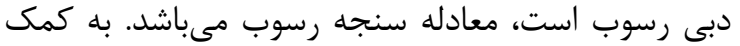

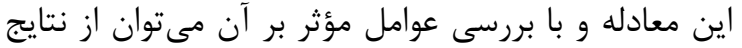

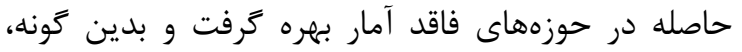

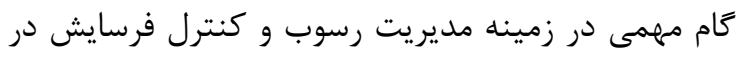

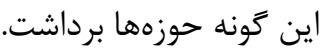

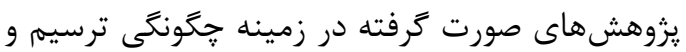

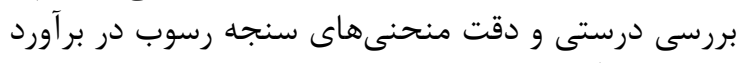

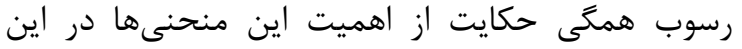

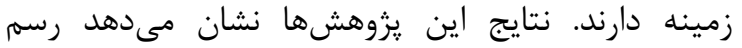

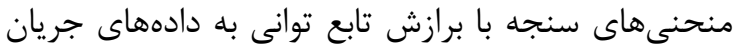

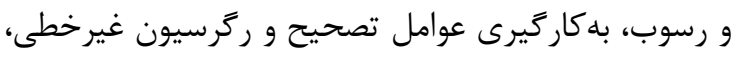

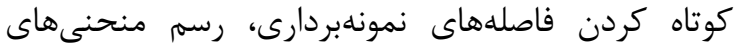

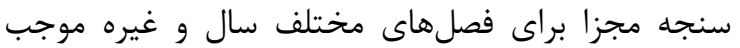

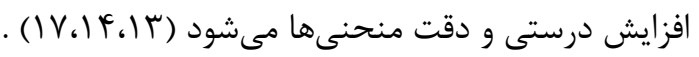




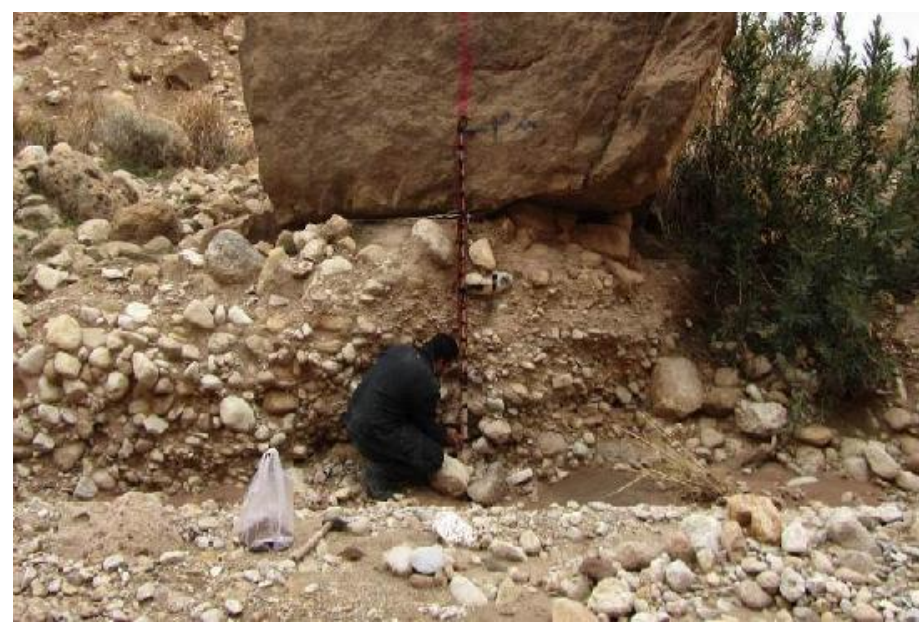

$$
\text { شكل هـ- نصب اشل در زيرحوزه r. }
$$

در اين رابطه، Q: دبى جريان برحسب مترمكعب بر ثانيه،

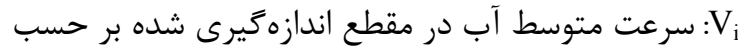
متر بر ثانيه، A

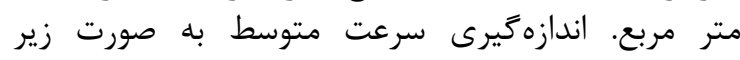

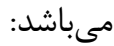

سرعت در سطح يك مقطع جريان توسط رابطه ب به مقيه سرعت متوسط در مقطع ارتباط مى يابد.

$V=K V_{s}$

رابطه (r)

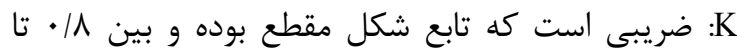

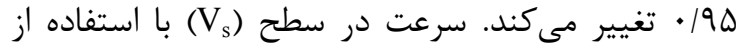

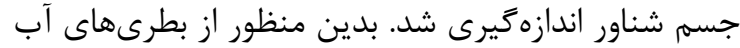

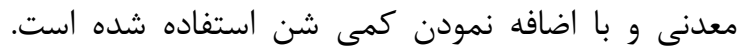

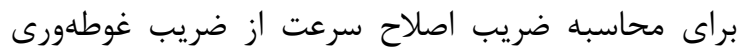

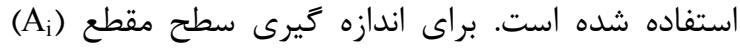

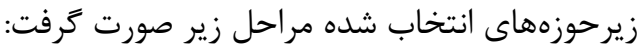

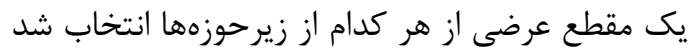

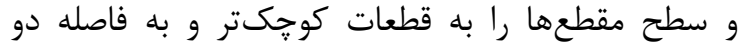

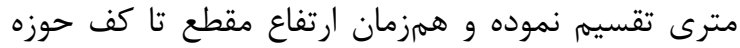

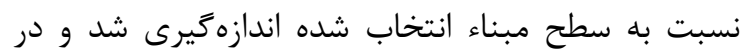

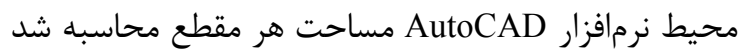

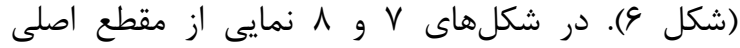

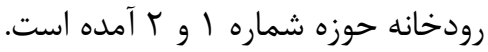

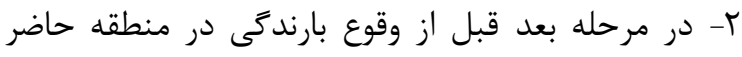

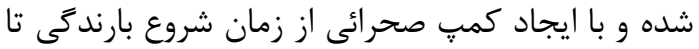

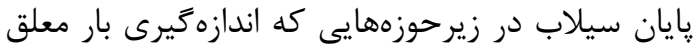

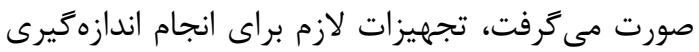

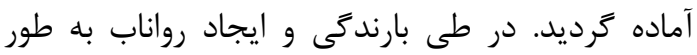

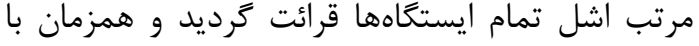

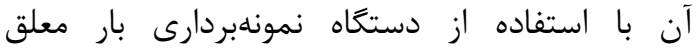

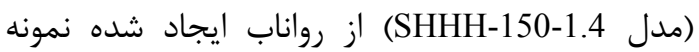

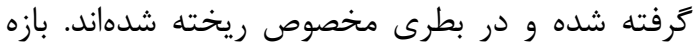

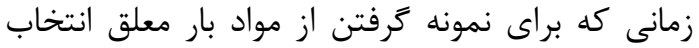

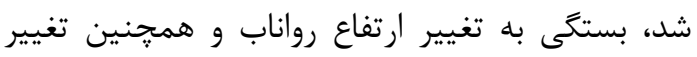

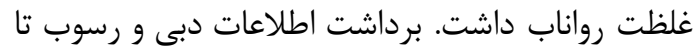

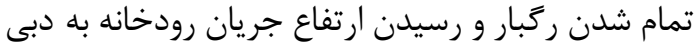

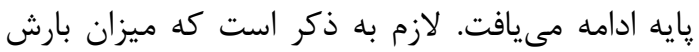

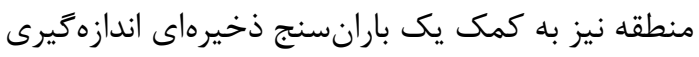
شده است. r- نمونههاى محتوى آب و رسوب بعد از هر ركبار برداشت و

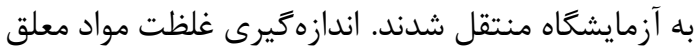

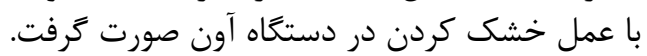

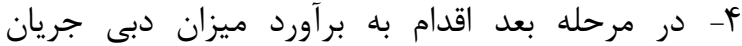
سيلابهاى رخ داده شد. براى اندازهذيرى دبى ديى جريان از رابطه r استفاده شد. $Q=V_{i} A_{I}$ (r) رابطه ابطه 

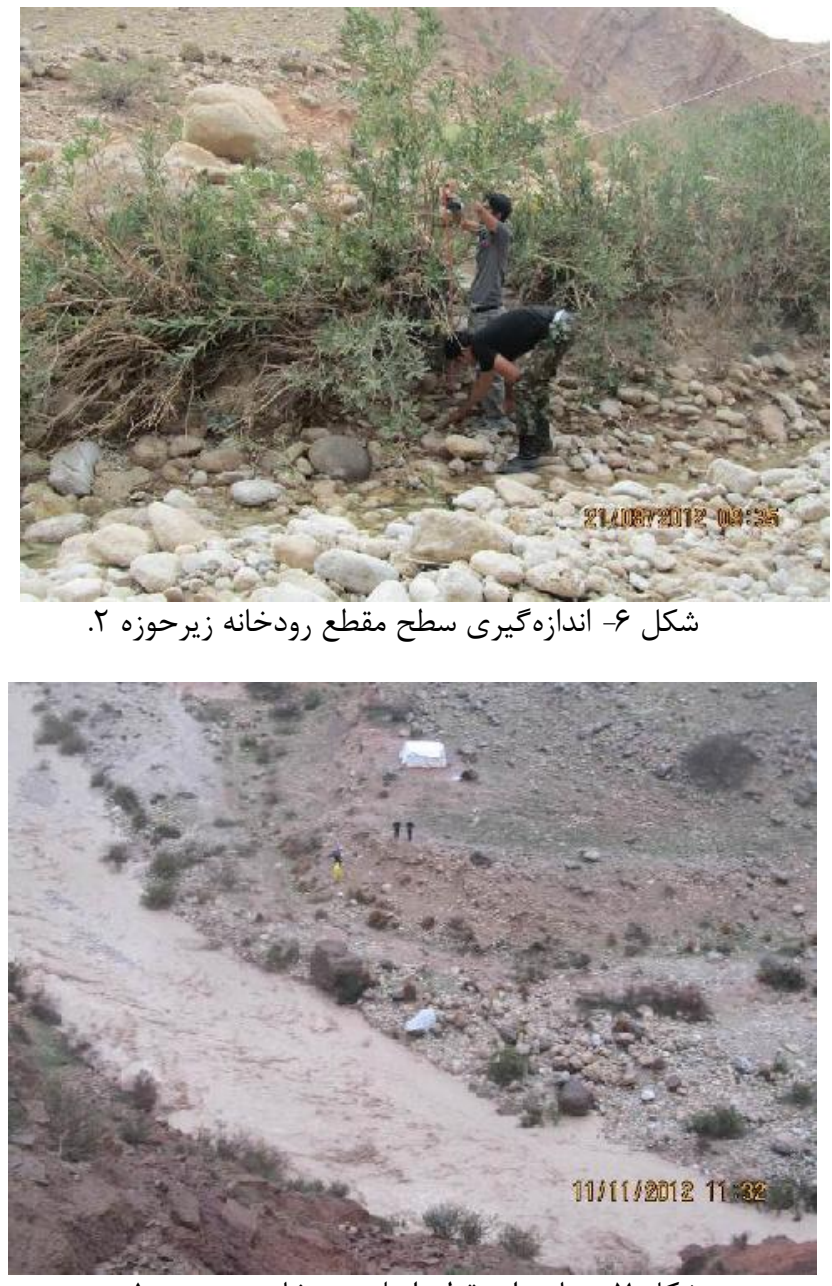

شكل V- نمايى از مقطع اصلى رودخانه زيرحوزه I.

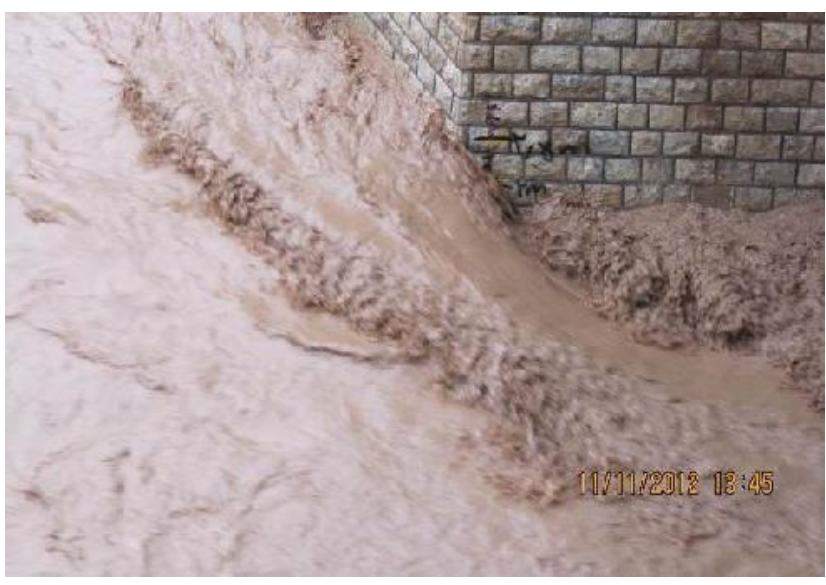

شكل ^- نمايى از مقطع اصلى رودخانه زيرحوزه ؟. 
تخمين ميزان نسبت تحويل رسوب' فئر

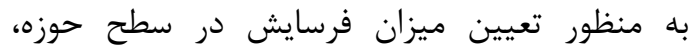

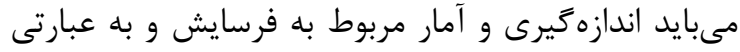

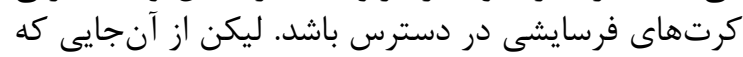

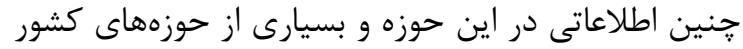

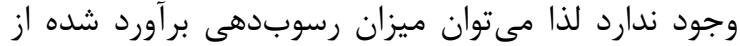

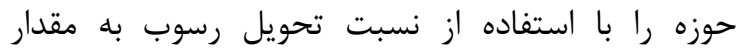

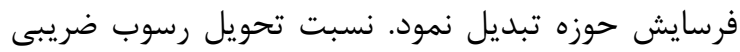

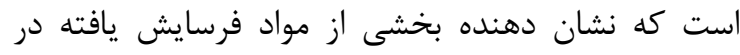

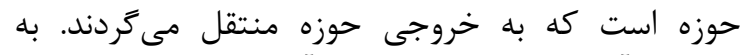

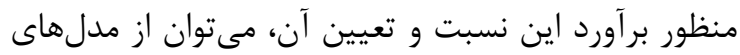

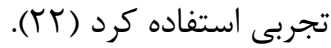

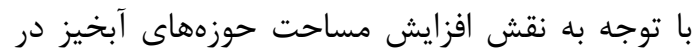

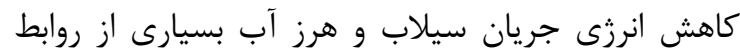

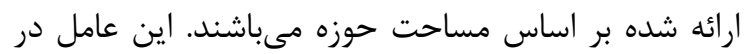

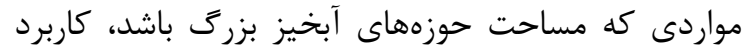

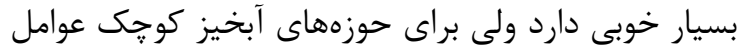

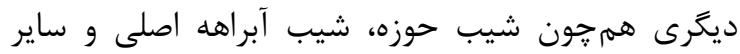

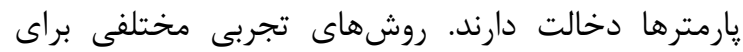

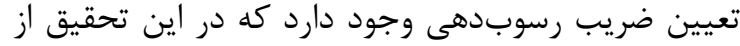

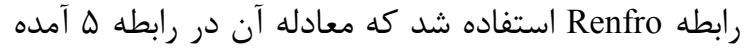

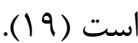

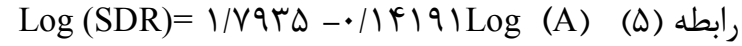

$$
\begin{aligned}
& \text { A مساحت حوزه به كيلومتر مربع. }
\end{aligned}
$$

\section{نتايج و بحث}

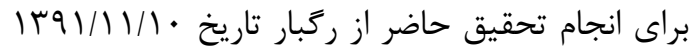

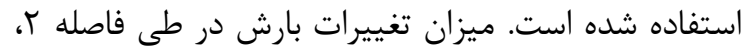

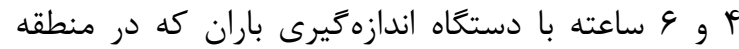

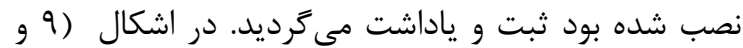

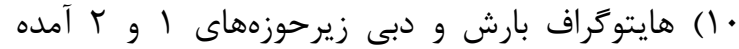

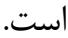

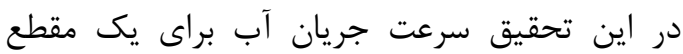

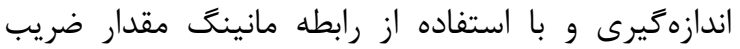

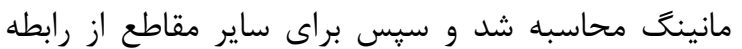

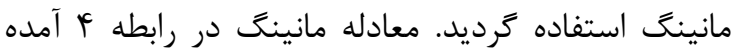

$Q=\frac{1}{n} S^{1 / 2} R^{2 / 3} A_{i}$

در اين رابطه، Q: دبى جريان برحسب مترمكعب بر ثانيه،

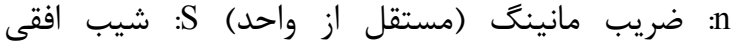

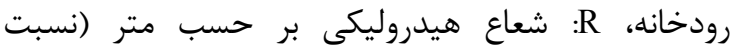

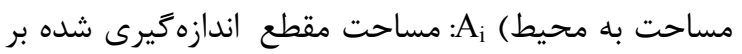

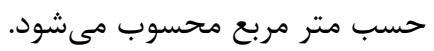

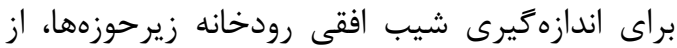

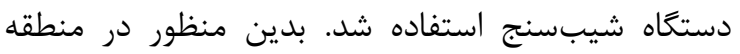

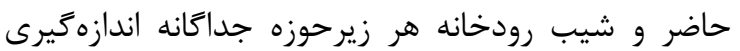

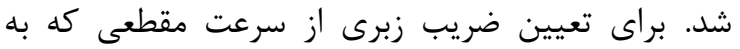

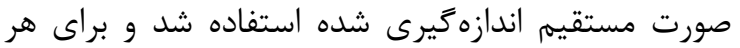

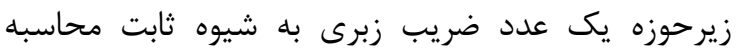

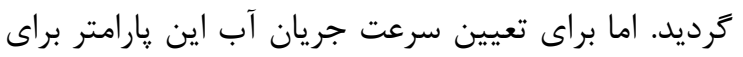
هر مقطع يك عدد به دست آمدي

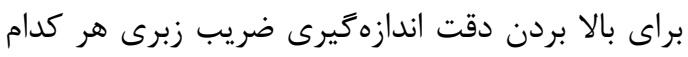

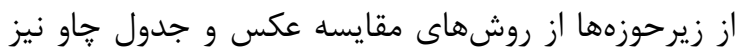

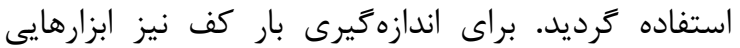

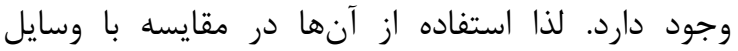

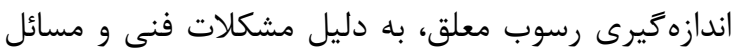

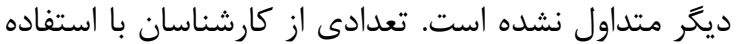

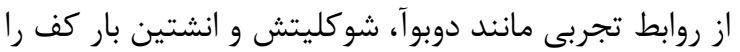

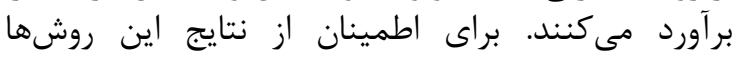

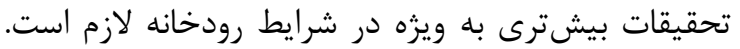

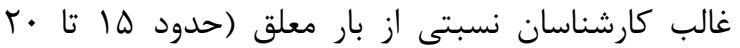

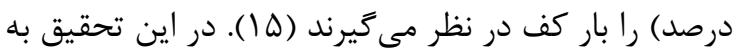

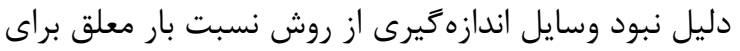
محاسبه بار كف سيلابها استفاده شد. 


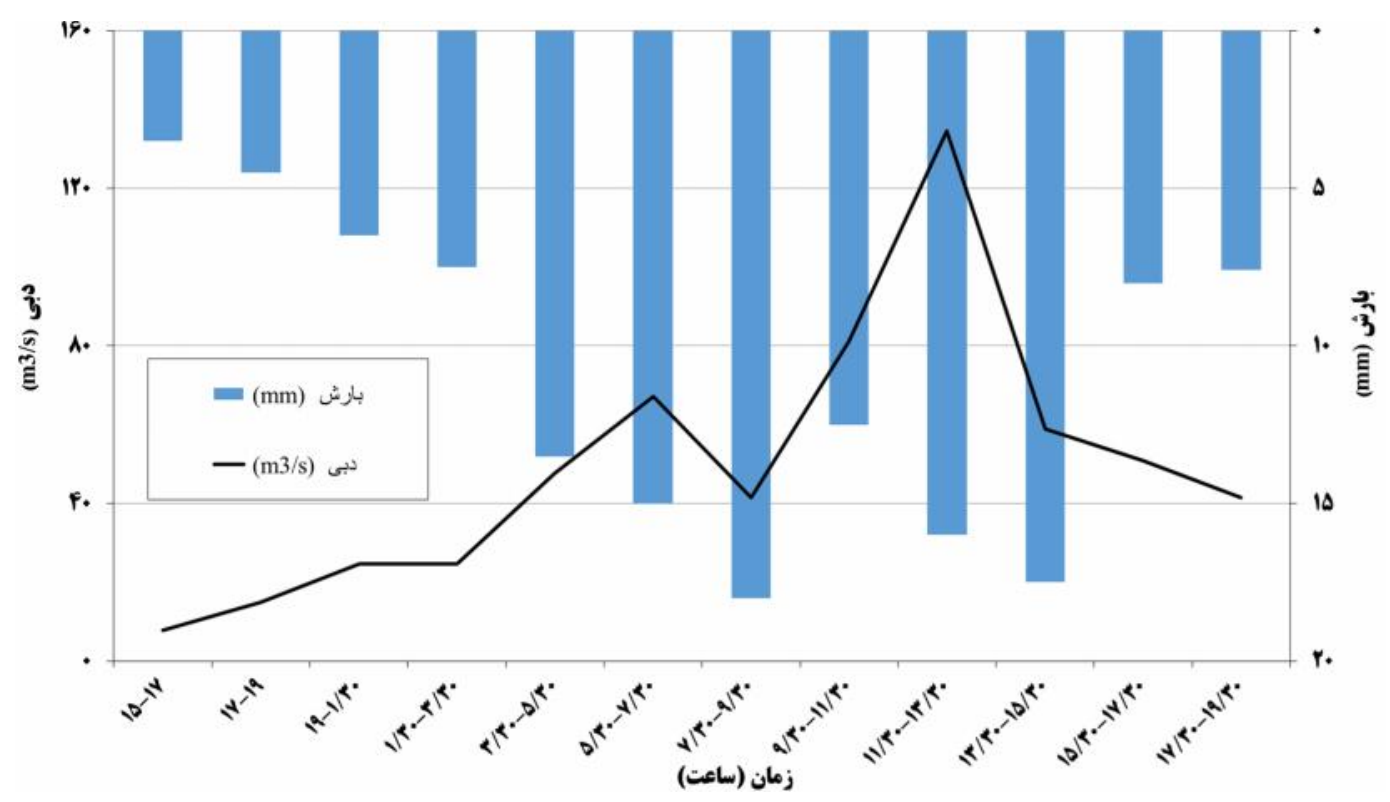

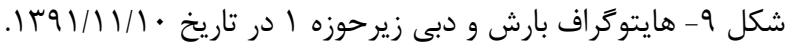

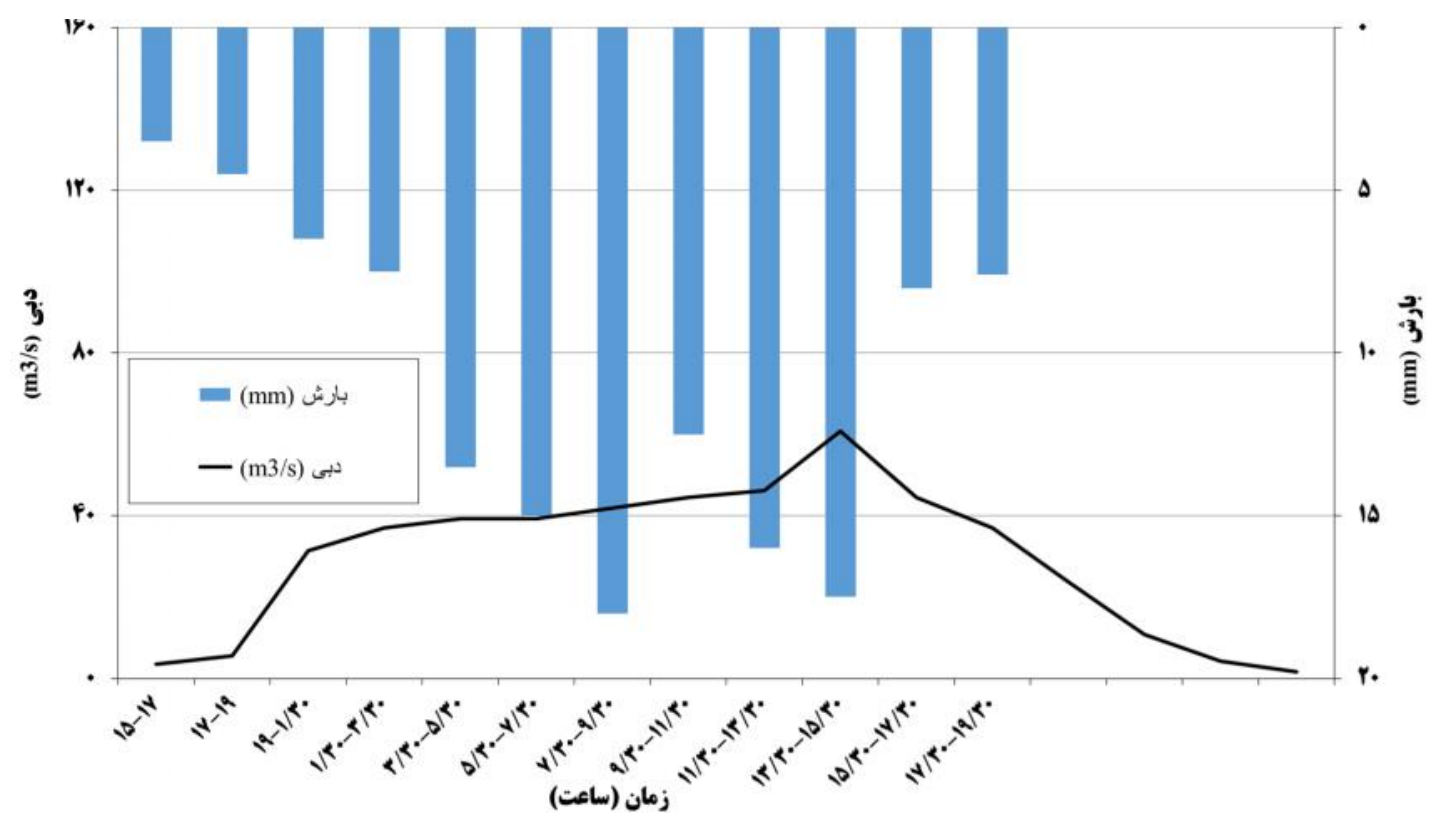

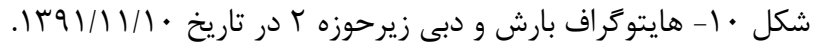

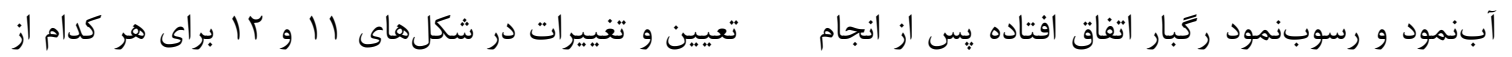
محاسبات لازم براى نمونهها برداشت شده از بار بار معلق زيرحوزهها ترسيم گرديد. 

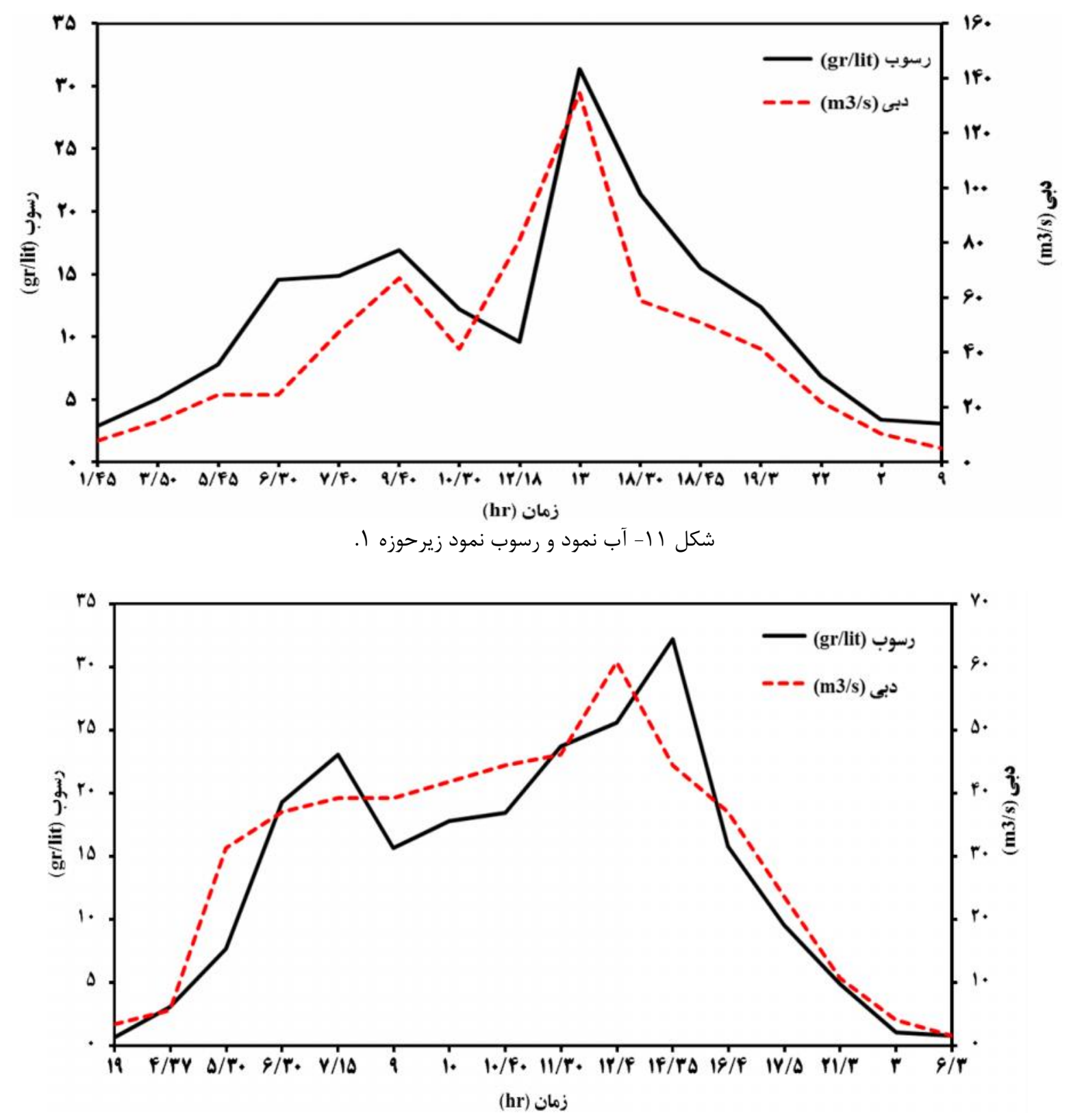

شكل rا- آب نمود و رسوب نمود زيرحوزه r.

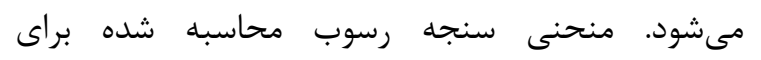

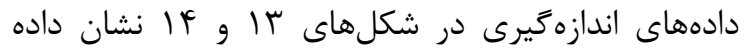

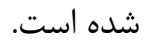

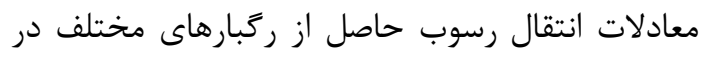

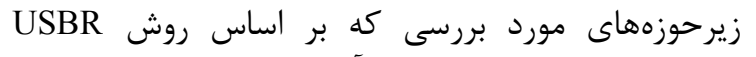

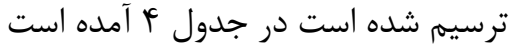

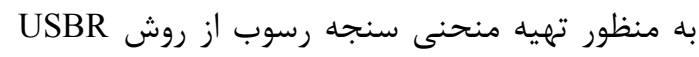

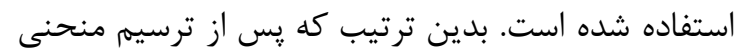

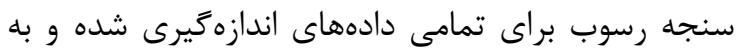

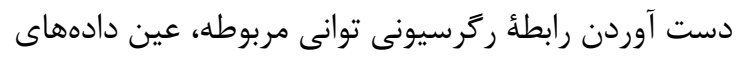

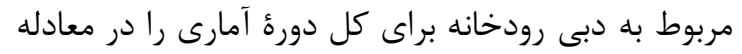

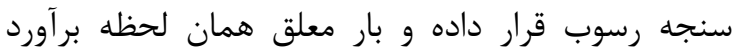




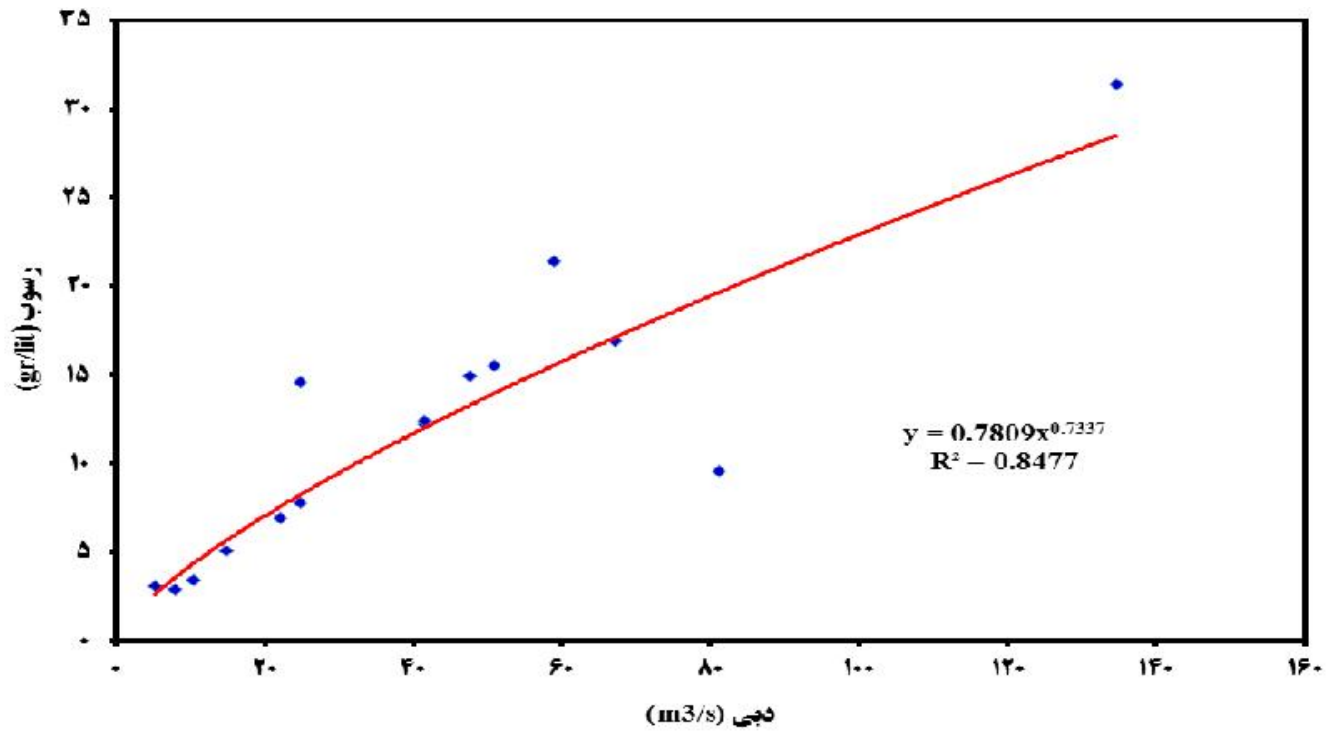

شكل r|- منحنى سنجه رسوب زيرحوزه ا.

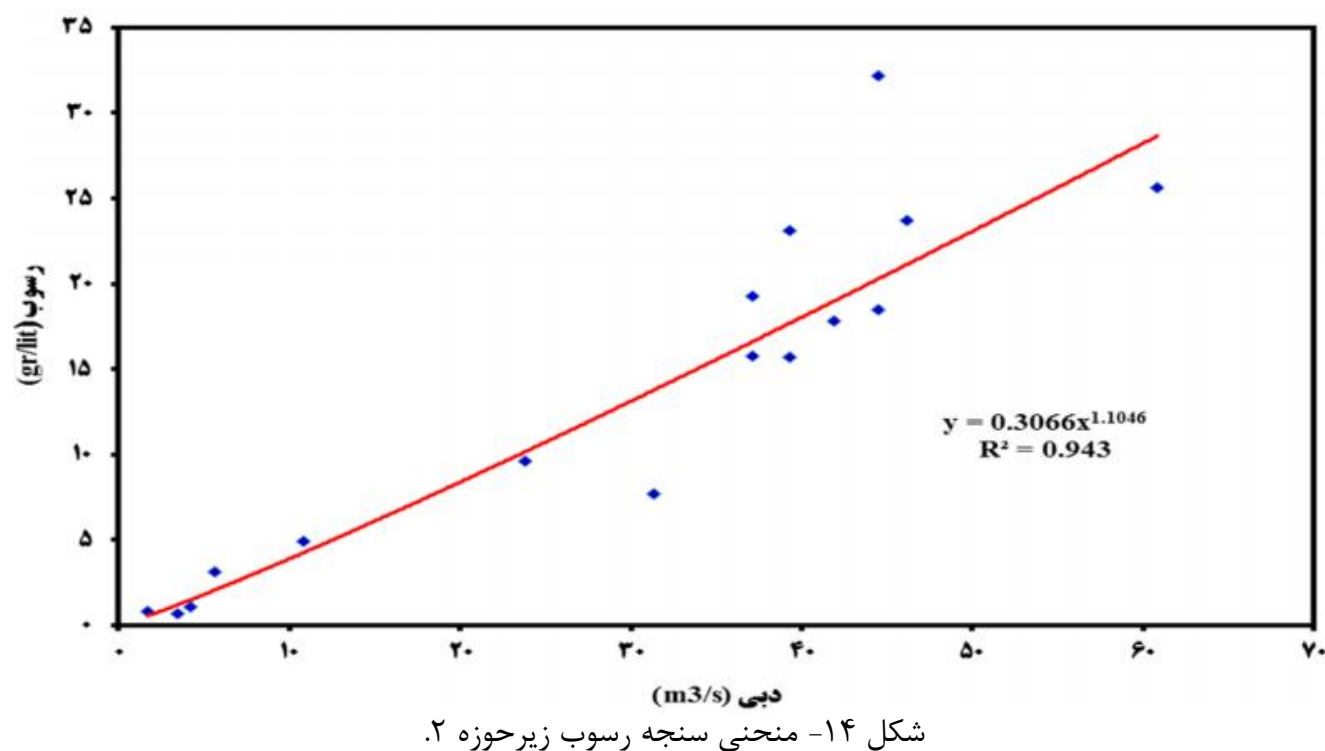

\begin{tabular}{|c|c|c|c|c|}
\hline & & \multicolumn{3}{|c|}{ جدول F أـ انواع معادلات سنجه رسوب بر اساس روش USBR } \\
\hline ضريب همبستىى & رابطه دبى - رسوب & تعداد دادهها & تاريخ ركبار & 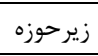 \\
\hline $\mathrm{R}^{2}=\cdot / \Lambda \mathrm{Q}$ & $Q_{s}=0.78 \quad \mathrm{Q}_{\mathrm{w}}^{0.7377}$ & 10 & $1 \% q 1 / 11 / 1$. & 1 \\
\hline $\mathrm{R}^{2}=. / 9 \mathrm{~F}$ & $Q_{s}=0.30 \mathrm{Q}_{\mathrm{w}}^{1.1046}$ & 19 & $1 \times 91 / / 1 / 1$. & r \\
\hline
\end{tabular}

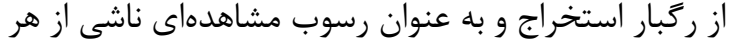

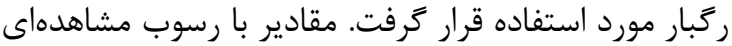

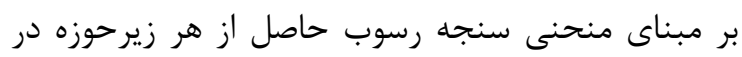
جدول ه آمده است.
براى برآورد بار رسوب مشاهدهاى، دادههاى مقطع و

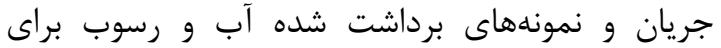

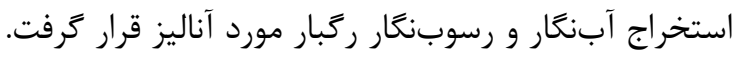

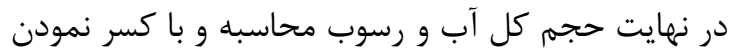

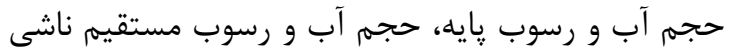


جدول ه- مقادير بارسوب مشاهدهاى هر يك از زيرحوزها

\begin{tabular}{|c|c|c|c|}
\hline رسوب ويزه (بر حسب تن/ هكتار) & بار رسوب مشاهدهاى از منحنى سنجه (برحسب تن) & تاريخ ركبار & 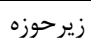 \\
\hline $19 / 0 T$ & IT\&八94 & $|r q| / 11 / 1$. & 1 \\
\hline $11 / r 4$ & $\Delta \cdots 1$ & $14 q 1 / 11 / 1$. & r \\
\hline
\end{tabular}

همان كونه كه كفته شد براى به دست آوردن مقدار كه نتايج به دست آمده از اين روش در جدول ع ع آمده

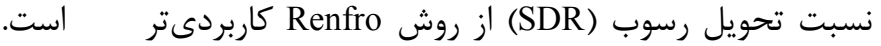
بوده و از سوى محققين مختلف توصيه شده، استفاده شد

جدول \&- مقادير نسبت تحويل رسوب در زيرحوزههاى مورد مطالعه با استفاده از روش Renfro

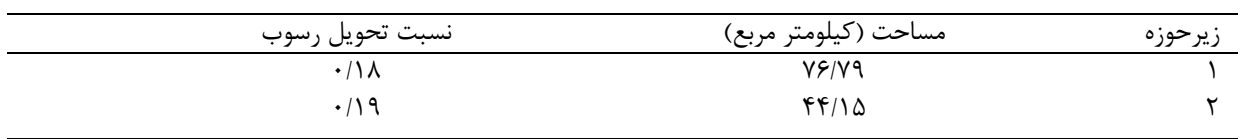

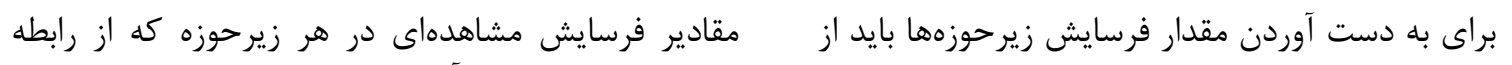

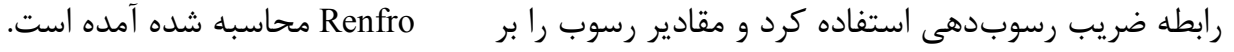

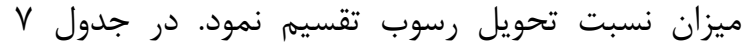

\begin{tabular}{|c|c|c|c|}
\hline فرسايش مشاهدهاى & بار رسوب مشاهدهاى & تاريخ رَبار & زيرحوزه \\
\hline 9944.9 & IrE人9F & $1491 / 11 / 1$. & 1 \\
\hline$r \Delta q \cdot V F$ & $\Delta \cdots 1$ & $\mid r q 1 / 11 / 1$. & r \\
\hline
\end{tabular}

سازندها براساس خصوصيات اقليمى منطقه با روش فيض

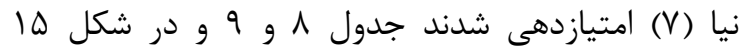

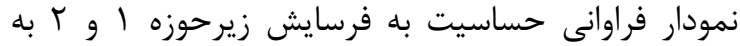
روش فيضنيا (V) آمده است.
آن جه مسلم است سختى سنَ، تنها يكى از عوامل

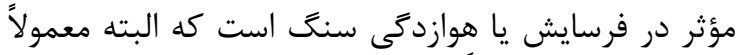

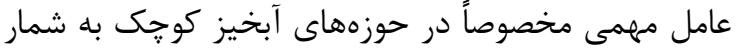

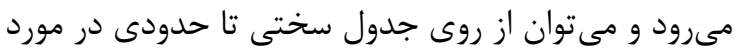

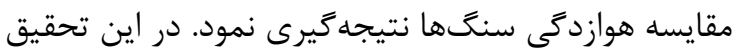

جدول ᄉ- امتيازدهى مقاومت سنگها در مقابل فرسايش به روش فيض نيا (V) "در زيرحوزه I"

\begin{tabular}{|c|c|c|c|}
\hline رده حساسيت به فرسايش & 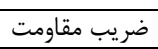 & نام سنَ & سازند \\
\hline متوسط & V & ماسه سنخ هاى آهكى نازك تا متوسط لايه به رنى قهوهاى & آغاجارى \\
\hline 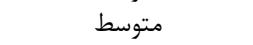 & 9 & آهكى سخت، كرمى رنغ، فسيل دارد و درز و شكاف دار & آسمارى \\
\hline حساس به فرسايش & $\Delta$ & لايههاى كنگلومرا و عدسىهايى از سيلتستون و ماسه سنگ & 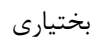 \\
\hline حساس به فرسايش & $\Delta$ & مارنهاى قرمز، ارغوانى، زيتونى، لايههاى سفيد گِّى، ايندريت و زيیِ & كَّساران \\
\hline حساس به فرسايش & f & شامل ذرات درشت دانه از قبيل قطعه سنَ و قلوه هاى درشت & 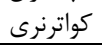 \\
\hline
\end{tabular}




\begin{tabular}{|c|c|c|c|}
\hline رده حساسيت به فرسايش & 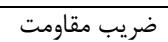 & نام سنَّ & سازند \\
\hline متوسط & $\mathrm{v}$ & ماسه سنك هاى آهكى نازك تا متوسط لايه به رنك قهوماى & آغاجارى \\
\hline متوسط & १ & آهكى سخت، كرمى رنكَ، فسيل دارد و درز و شكاف دار & آسمارى \\
\hline حساس به فرسايش & $\Delta$ & لايههاى كنغلومرا و عدسى هايى از سيلتستون و ماسه سنَ & بختيارى \\
\hline حساس به فرسايش & $\Delta$ & مارن هاى قرمز، ارغوانى، زيتونى، لايه هاى سفيد كَّى، ايندريت و ريّيس & كَّساران \\
\hline متوسط & $\mathrm{v}$ & 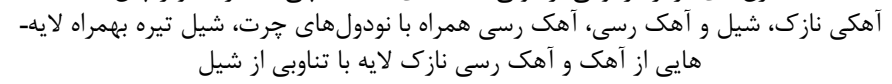 & يابده-كوريى \\
\hline حساس به فرسايش & r & شامل ذرات درشت دانه از قبيل قطعه سنَ و قلوه هاى درشت & كواترنرى \\
\hline
\end{tabular}

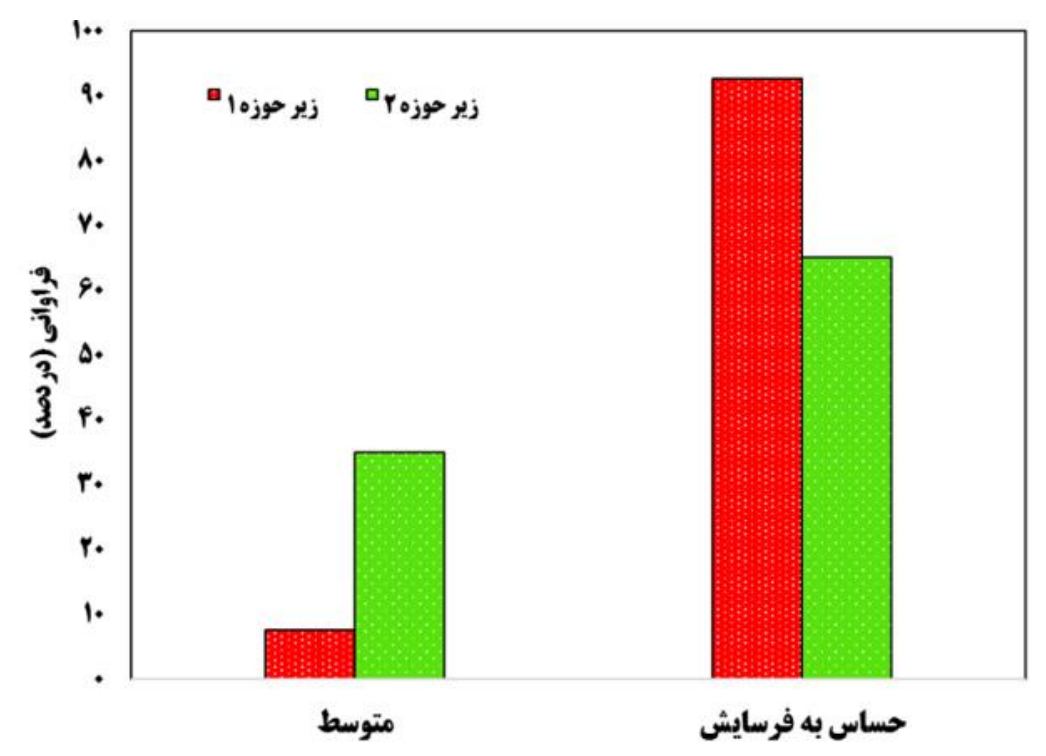

شكل Qا - فراوانى حساسيت به فرسايش زيرحوزه ا و r به روش فيضنيا (V).

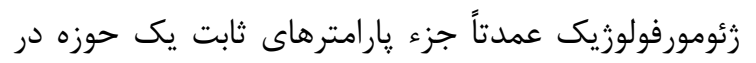

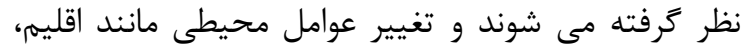

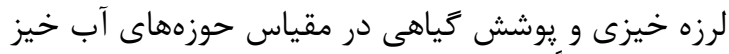

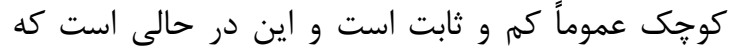

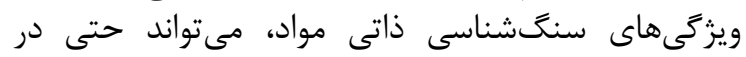

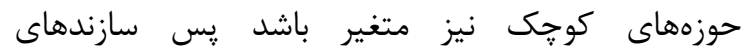
زمينشناسى دو زيرحوزه بر اساس روش فيض فيضنيا

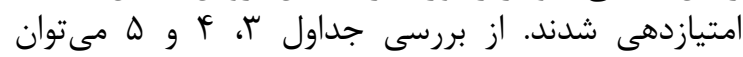

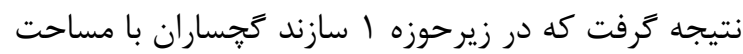

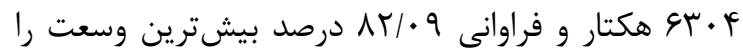

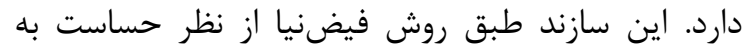

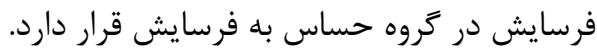

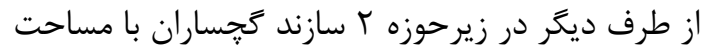

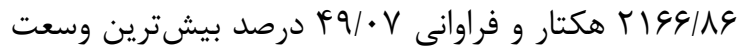

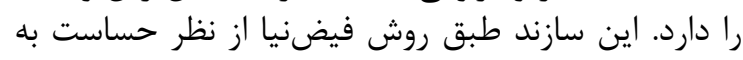

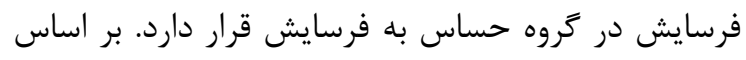

هدف از تحقيق حاضر، بررسى مقاومت سازندهاى

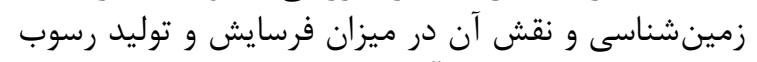

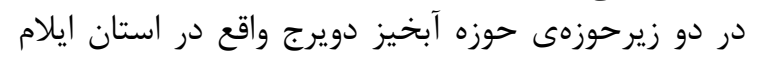
مىباشد.

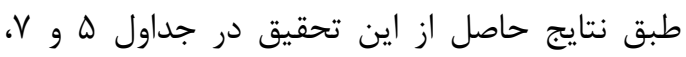

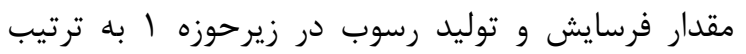

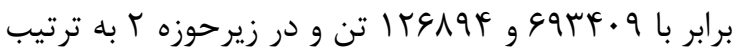

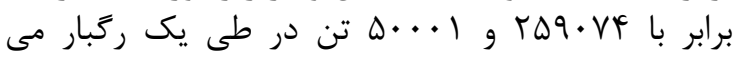

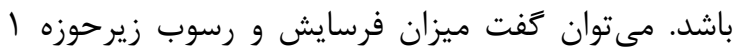

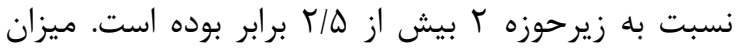

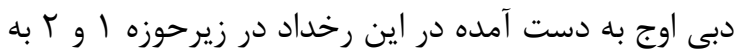

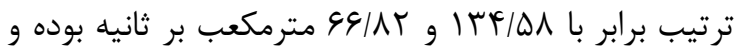

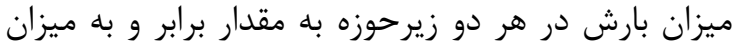

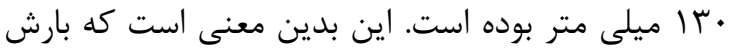

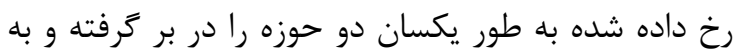

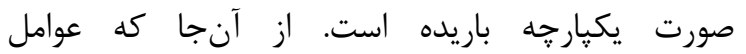




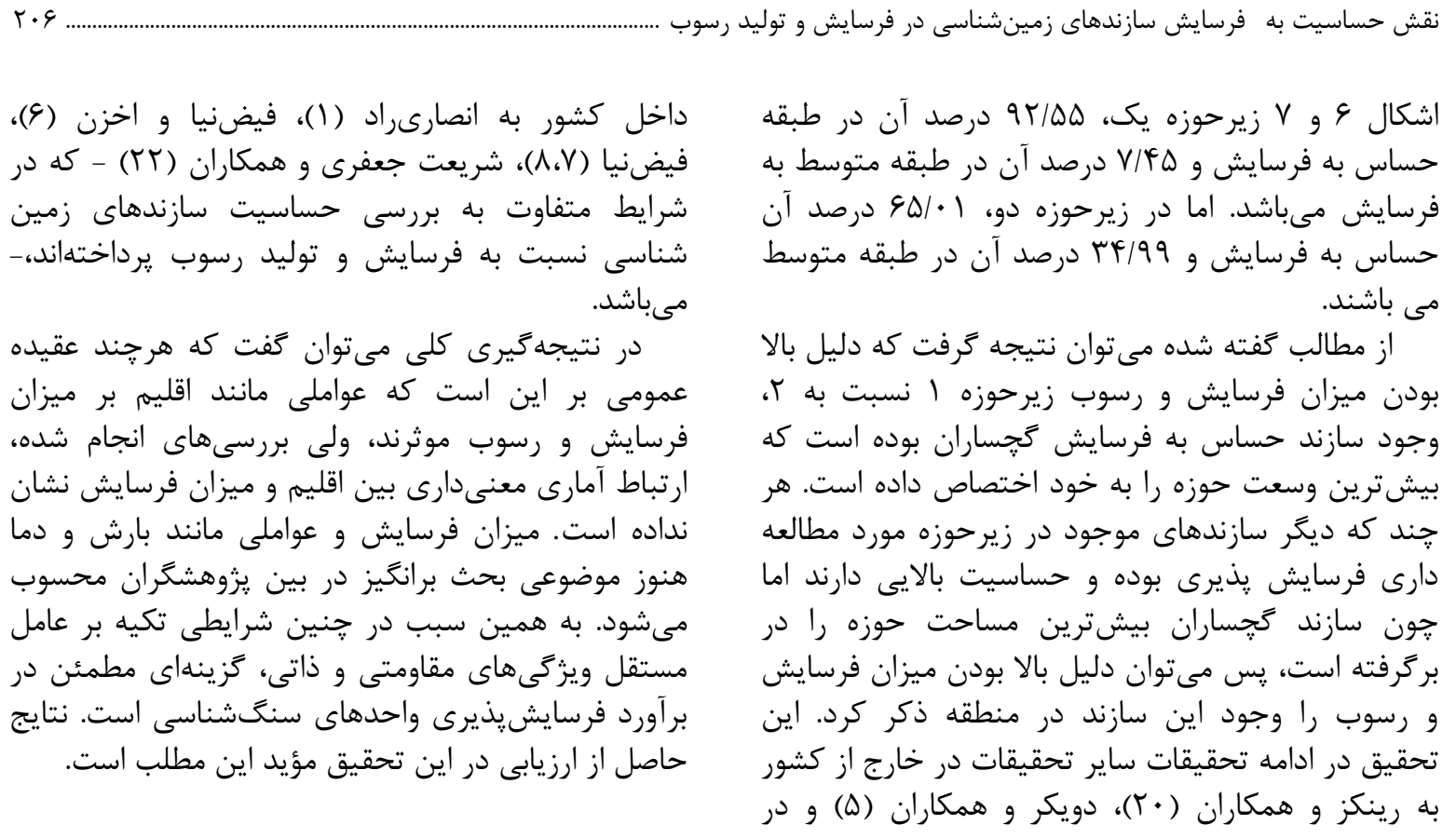

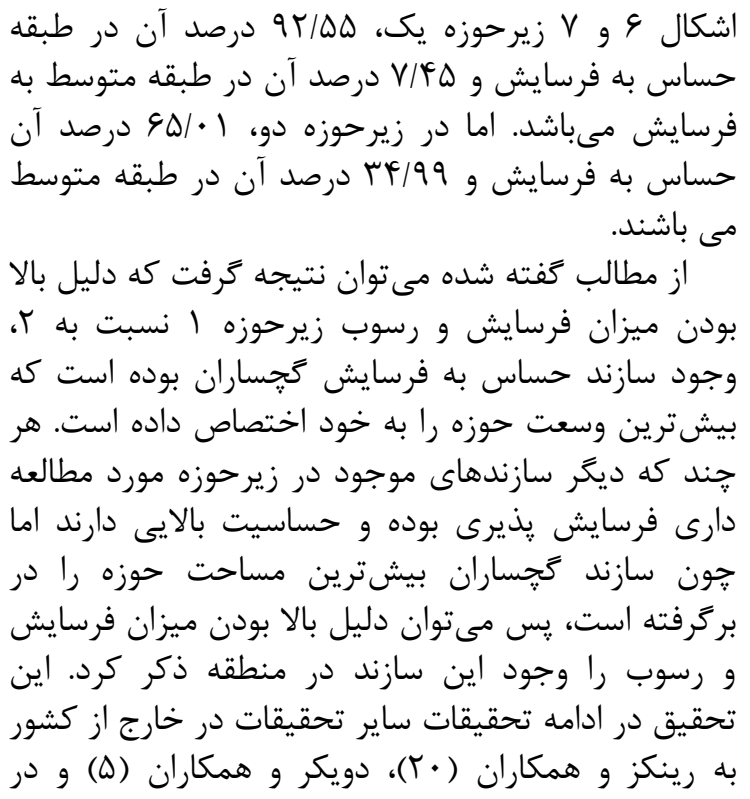

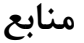

1. Ansari Rad, P. 2008. Mapping Susceptibility to Erosion and Determining the Fancies Erosion Stony unit's basin Chandab. $3^{\text {th }}$ Conference on Applied Geology and Environmental, 15 pp (In Persian).

2. Arabkhedri, M. 2001. Report Research Project Estimate Special Deposition in the Country. Research Center Soil and Watershed Management, 54 pp (In Persian).

3. Arabkhedri, M. and SH. Hakim Khani. 2001. Validity of Extrapolation Methods for Estimating the Mean Annual Suspended Sediment yield (17 hydrometric Stations in the Country). Journal of Agriculture and Natural Resources Journal of Agricultural Sciences and Natural Resources, 3: 123-132 (In Persian).

4. Brown, A.G., C. Carey, G. Erkens, M. Fuchs, T. Hoffmann, J.J. Macaire, K.M. Moldenhauer and D.E. Walling. 2009. from Sedimentary Records to Sediment Budgets: Multiple Approaches to Catchment Sediment Flux: Geomorphology, 108: 35-47.

5. Duiker, S.W., D.C. Flanagan and R. Lal. 2001. Erodibility and Infiltration Characteristics of Five Major Soils of Southwest Spain. Catena, 45: 103-121.

6. Feiznia, S. and K. Akhzn. 2008. Amount Determination of Erosion and Erosion Index Formations Damavand Watershed of Sediment Logical Method. $3^{\text {th }}$ Conference on Applied Geology and Environmental, $15 \mathrm{pp}$ (In Persian).

7. Feiznia, S. 1995. Rock Resistance against Erosion in Different Climates Iran. Journal of Natural Sources of Iran, 47: 95-116 (In Persian).

8. Feiznia, S. 1996. Rocks Resistance against Erosion in Different Climates of Iran, Journal of Natural Resources, 47: 95-116 (In Persian).

9. Feiznia, S. and M. Khosh Eghbal. 2004. Sensitivity of Rocks and Formations to Erosion and Sediment Yield in Latian Drainage Basin Area. Journal of Natural Resources, 54: 365-382 (In Persian).

10. Ghzanchayy, R. and A. Faryab. 2006. Assessment of Erosion in Forests and Agricultural Land Use of the EPM Approach. $9^{\text {th }}$ Congress of Soil Science. Karaj, 578-582 (In Persian).

11. Hakim Khani, SH., M. Arabkhedri, M. Mahdavi and A. Khvjyny. 1998. Regional Analysis of Suspended Sediment in the Basin of Lake Urmia. $2^{\text {th }}$ National Conference Erosion and Sedimentation, 11 pp (In Persian).

12. Hovius, N. 1998. Controls on Sediment Supply by Large Rivers, in Shanley, K.W., ed., Relative Role of Ecstasy, Climate, and Tectonic in Continental Rocks: SEPM (Society for Sedimentary Geology) Special Publication, 59: 3-16.

13. Jones, S.J. 2004. Tectonic Controls on Drainage Evolution and Development of Terminal Alluvial Fans, Southern Pyrenees. Spain, Terra Nova, 16: 121-127.

14. Kerem, H.C. 2003. Estimation and Forecasting Daily-Suspended Sediment Data by Multilayer Perceptions. Advances in Water Resources, 27: 185-195. 
15. Mahdavi, M. 2008. Applied Hydrology, Tehran University Press, Fifth Edition, 427 pp (In Persian).

16. Milliman, J.D. and J.P.M. Syvitski. 1992. Geomorphic/tectonic Control of Sediment Discharge to the Ocean, Journal of Geology, 100: 525-544.

17. Mirzaei, M.R. 2002. A Comparison of Methods of Estimation of Suspended Sediment in Rivers. M.Sc. Thesis, Department of Natural Resources. Tehran University, 148 pp (In Persian).

18. Morgan, R.P.C. 2005. Soil Erosion and Conservation. Longman. 298 pp:

19. Pazhohesh, M., M. Gorgi, S.M. Taheri, F. Sarmadian, J. Mohammadi and H.S. Borojeni. 2011. Effects of Different Land Uses in the Upper Basin Dam Sediment Yield Using GIS Zayandehrud. Study of water, 5: 143-52 (In Persian).

20. Riebe, C.S., J.W. Kirchner, D. E. Granger and R.C. Finkel. 2001. Minimal Climatic Control on Erosion Rates in the Sierra Nevada, California. Geological Survey of America, Geology, 29: 447-450.

21. Rienks, S.M., G.A. Botha and J.C. Hughes. 1999. Some Physical and Chemical Properties of Sediments Exposed in a Gully (Donga) in Northern KwaZulu-Natal, South Africa and Their Relationship to the Erodibility of the Colluvial Layers, Catena, 39: 11-31.

22. Rostami, N. 2005. Select the Best Method for Estimating SDR in Ilam Dam Basin, M.Sc. Thesis of Watershed, Department of Natural Resources, Tehran University, Karaj, 125 pp (In Persian).

23. Shariat Jafari, M., M. Ghayoumian and H.R. Provan. 2007. The Inherent Sensitivity of Geological Formations to Erosion and Weathering in Basins of Micro Continental Plate of Central Iran, Journal of Science Tarbiat Moallem University, 1: 709-723 (In Persian).

24. Sui, J.Y. He and C. Liu. 2009, Changes in Sediment Transport in Kuye River in the Loess Plateau in China. International Journal of Sediment Research, 24: 201-213.

25. Summerfield, M.A. and N.J. Hulton. 1994. Natural Controls on Alluvial Denudation Rates in Major World Drainage Basins Journal of Geophysical Research, Solid Earth, 99: 13871-13883.

26. Vent, T.D. and J. Poesen. 2005. Predicting Soil Erosion and Sediment Yield at the Basin Scale: Scale Issue and Semi-Quantitative Models. Earth- Science Reviews, 71: 95-125.

27. Walling, D.E. and B.W. Webb. 1983. Patterns of sediment yield. In: Background to Palaeohydrology (ed. by K. J. Gregory), 69-100. Wiley, Chichester, UK.

28. Warren, S.D., H. Milasova, M.O. Hohmann, S. Landsberger, F.Y. Iskandar, T.S. Ruzycki and G.M. Senseman. 2005. Validation of a 3-d Enhancement of the Universal Soil Loss Equation, 12: 387-415.

29. Ziaie, H.A. 2001. Principles of Watershed Management Engineering. University of Imam Reza (AS). 542 pp (In Persian). 


\title{
Role of Sensitivity of Erosion the Geological Formations at Erosion rate and Sediment Yield (Case Study: Sub-Basins of Doviraj River, Ilam Province)
}

\author{
Hassan Fathizad ${ }^{1}$, Haji Karimi ${ }^{2}$ and Mohsen Tavakoli $^{3}$

\begin{tabular}{c} 
Hassan Fathizad , Haji Karimi \\
\hline \hline 1 and 3- Graduated M.Sc. and Assistant Professor, Ilam University \\
2- Associate Professor, Ilam University (Corresponding author: h.karimi@mail.ilam.ac.ir) \\
Received: November 14, $2013 \quad$ Accepted: March 4, 2014 \\
\hline
\end{tabular}

\begin{abstract}
Studies related to erosion and soil conservation of litho logical and geological characteristics of catchments have particular importance, Due to their effects. Erosion and sediment production are related to many factors, in which, the sensitivity of geological formation to erosion is the most important parameter. In this study, formations sensitivity to erosion in two sub-basins of Doviraj River located in Ilam Province is compared and their role in erosion and sediment yield has been investigated. In order to study the sensitivity of geological formations the Faiznia (1996) method is used. Results showed that the erodibility of the geological formations has a significant role in the erosion and sediment production, so that, the erosion and sediment yield of the first catchment is 2.5 times as much as the second catchment, because $92.4 \%$ of the sub-basin 1 , is classified as sensitive to erosion and $7.45 \%$ the average class of sensitivity, but in the sub-basin 2 , the above amounts are $65.01 \%$ and $34.99 \%$ respectively. Also, in the sub-basin 1, the Gachsaran formation which covers 6304 hectares $(82.09 \%$ of the catchment) has the highest frequency and the above figure in the subbasin 2, is 2166.86 hectares (49.07\% of the catchment). Higher erosion and sediment yield of the sub-basin 1 compared to the sub-basin 2 is due to the existence of sensitive formation to erosion, especially Gachsaran formation which has the highest frequency in the study area.
\end{abstract}

Keywords: Doviraj, Erosion, Feyznia Method, Geological Formations, Sediment 